\title{
Non-alcoholic Fatty Liver Disease in South Asians: A Review of the Literature
}

\author{
Sital Singh ${ }^{1}$, Gabriela N. Kuftinec ${ }^{2}$ and Souvik Sarkar*1 \\ ${ }^{1}$ Division of Gastroenterology and Hepatology and Department of Internal Medicine, University of California, Davis, USA; \\ ${ }^{2}$ Department of Internal Medicine, University of California, Davis, USA
}

\begin{abstract}
Non-alcoholic fatty liver disease (NAFLD) and non-alcoholic steatohepatitis (NASH) are national and global epidemics. The disease is characterized by a spectrum of liver steatosis (fat deposition), inflammation (in NASH) and fibrosis. NAFLD and specifically NASH can lead to cirrhosis, which carry risks of progression to portal hypertension and hepatocellular carcinoma (HCC). NASH is also associated with higher mortality from cardiovascular causes. Most of the data for NAFLD has been obtained from the perspective of developed nations, although the disease is increasing and threatening to reach epidemic proportions across the world. Emerging data is notable for high prevalence of NAFLD in South Asian populations, presumably resulting from a combination of underlying genetic polymorphisms and changes in socio-economic status. It is also notable that an 'Asian Paradox' has been defined for NAFLD based upon the observation of lower than predefined body mass index (BMI), otherwise termed as "lean NAFLD", among this population. Yet, data remains limited in regards to the characteristics of NAFLD/NASH in this population. In this article, we present a review of the literature and discuss the prevalence, associated risk factors and burden of $\mathrm{HCC}$ in South Asians with NAFLD.
\end{abstract}

Citation of this article: Singh S, Kuftinec GN, Sarkar S. Nonalcoholic fatty liver disease in South Asians: a review of the literature. J Clin Transl Hepatol 2017;5(1):76-81. doi: 10. $14218 / \mathrm{JCTH} .2016 .00045$.

\section{Introduction}

Non-alcoholic fatty liver disease (NAFLD) is a major cause of chronic liver disease globally, and is characterized by a spectrum of steatosis, inflammation and fibrosis. Non-alcoholic steatohepatitis (NASH) is a more severe form of NAFLD, and is characterized by lobular inflammation and hepatocyte

Keywords: Non-alcoholic fatty liver disease (NAFLD); Non-alcoholic steatohepatitis (NASH); South Asia.

Abbreviations: NAFLD, non-alcoholic fatty liver disease; NASH, non-alcoholic steatohepatitis; HCC, hepatocellular carcinoma; BMI, body mass index; US, ultrasound; HOMA-IR, homeostatic model assessment of insulin resistance; SNPs, single nucleotide polymorphisms.

Received: 17 September 2016; Revised: 10 December 2016; Accepted: 05 January 2017

*Correspondence to: Souvik Sarkar, Division of Gastroenterology and Hepatology and Department of Internal Medicine, University of California, $4150 \mathrm{~V}$ Street, PSSB 3500, Sacramento, CA 95817, USA. Tel: +1-916-734-3759, Fax: +1-916-7347908, E-mail: ssarkar@ucdavis.edu ballooning; ${ }^{1,2}$ furthermore, NASH is presumed to lead to cirrhosis in a quarter of the afflicted patients.

The growth of NAFLD as an epidemic is related to increasing prevalence of obesity and sedentary life-style. The traditional risk factors for NAFLD include age, sex, central obesity leading to insulin resistance, and development of metabolic syndrome. Furthermore, genetic predisposition is also presumed to have a role, given the differences noted amongst different ethnic groups. ${ }^{3,4}$ In the United States, the prevalence of NAFLD is gradually increasing and is currently estimated to affect one-third of adults. ${ }^{1-5}$ Moreover, NASH is predicted to be the leading cause of liver transplant in the coming years. Despite the growing prevalence, however, the treatment options remain extremely limited.

Until recently, NAFLD was believed to be a disease of the industrialized world, primarily related to sedentary life-style. However, a growing body of literature has highlighted NAFLD as a global epidemic. Studies have suggested a wide amount of diversity in prevalence based on country of interest. The average prevalence in Europe is $20-30 \%$ and in China appears to be $5-24 \% .^{1,5}$ In India, the prevalence is estimated to be between $16-32 \% .^{5}$ This is believed to be due to the increasing industrialization of these nations, along with changes in lifestyle and diet. Furthermore, recent studies have also suggested that NASH/NAFLD can also affect seemingly non-obese Asians. ${ }^{6,7}$ This has come to be known as the 'Asian Paradox'as a disease that is associated with high BMI in the Western world may not predict accurately the risk of developing NAFLD in the Asian world. ${ }^{6-8}$

In this review, we look specifically at South Asians afflicted with NAFLD. South Asia is a growing epicenter for industrialization and changing life-styles, and also increasing prevalence of NAFLD. The South Asian region includes the countries of India, Nepal, Bhutan, Bangladesh, Sri Lanka, Maldives, Pakistan and Afghanistan. The available data from these regions remains limited. The importance of gaining a better and complete understanding NAFLD in this region is essential in view of its growing population and immigration to Western nations. In this review, we describe the prevalence of NAFLD in South Asians and further describe the NAFLD phenotype with respect to 'lean NAFLD' as well as the burden of hepatocellular carcinoma (HCC) in South Asia.

\section{Methods}

We undertook a comprehensive search for related articles using two different databases. Articles were restricted to the English language. First, we searched the PubMed database using the terms "NASH and South Asia", "NAFLD and South 
Asia", non-alcoholic liver disease and South Asia", "non-alcoholic steatohepatitis and South Asia", and "fatty liver and South Asia". Furthermore, we followed up this wide search for articles with a subsequent search using the terms "NAFLD" and individual countries comprising South Asia (i.e. Afghanistan, Bangladesh, Bhutan, India, Nepal, Maldives, Pakistan and Sri Lanka). Additionally, we performed an Embase database search for the period from 1980 to 2016 with the search terms "NASH and South Asia," "NAFLD and South Asia," "non-alcoholic liver disease and South Asia," "nonalcoholic steatohepatitis and South Asia," along with "fatty liver and Asia". The last terms used for this comprehensive search were "NAFLD and (Afghanistan, Bangladesh, Bhutan, India, Nepal, Maldives, Pakistan or Sri Lanka)."

The studies that were included in the review were those with diagnosis of NAFLD either by aid of ultrasound (US) or biopsy. We did not exclude studies based on study participants' age, degree of obesity, insulin resistance or diabetes (Type 1 diabetes or Type II diabetes). We also did not exclude studies based on type of center or geographical location (rural vs. cosmopolitan center, or tertiary referral center vs. community hospital).

\section{Prevalence of NAFLD/NASH in South Asia}

Several small population-based studies were reviewed, which provided estimates of NAFLD prevalence across South Asian nations (Fig. 1). Most of the studies, though, were from India, with a few studies from the other nations. A caveat to consider is that the true prevalence of NASH is unclear, as diagnosis via biopsy is limited, with the majority of the data provided by US detection. Also, the studies did not always differentiate clearly between tertiary and non-tertiary centers, which can confound the data due to differences of availability of diagnostic testing. Of the few studies that utilized liver biopsy, there was estimation of prevalence in patients undergoing bariatric

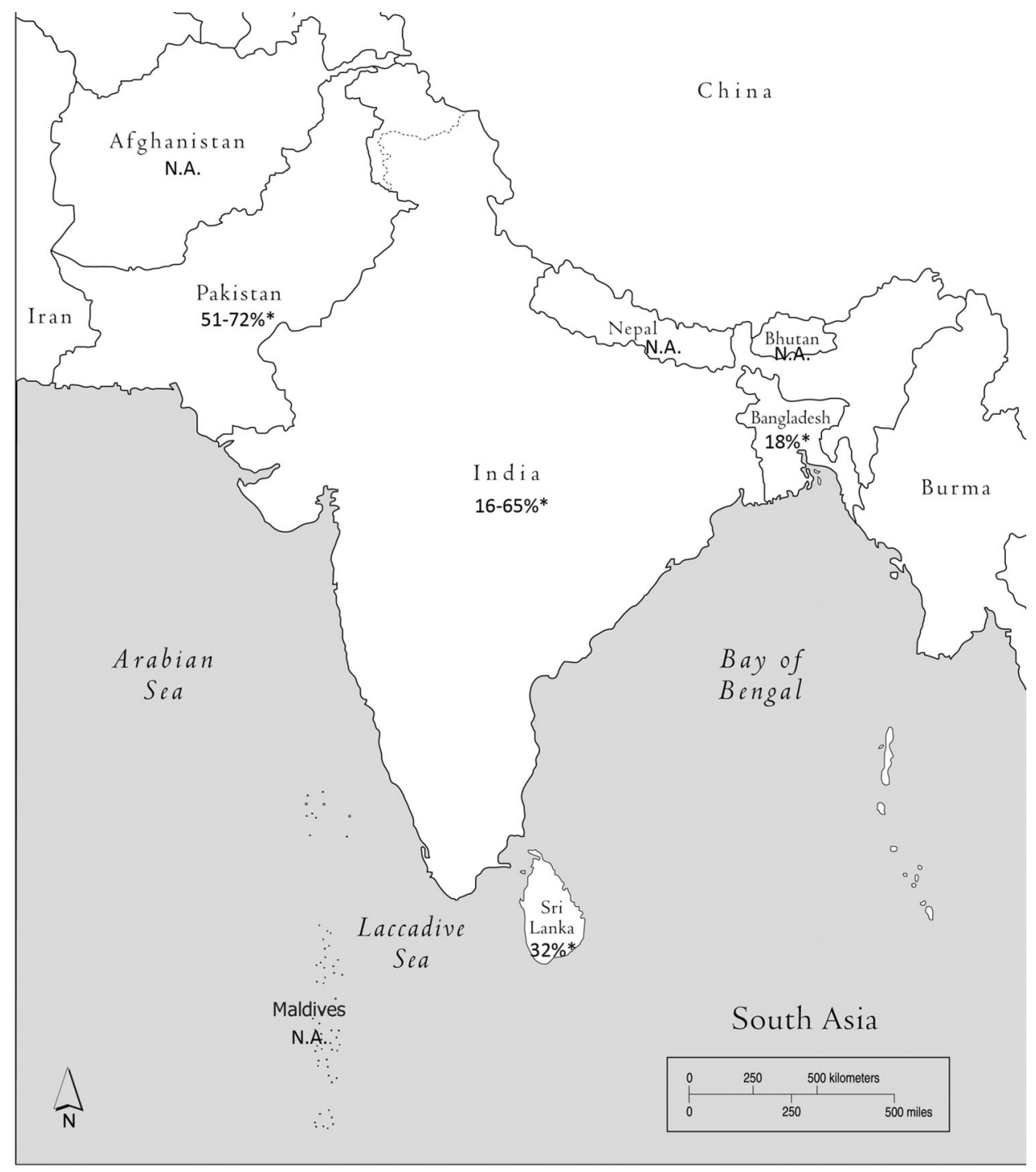

*Estimated prevalence; N.A.: not available

Fig. 1. Estimated NAFLD/NASH prevalence in South Asia. 
Singh S. et al: NAFLD in South Asians

Table 1. Prevalence of NAFLD in various South Asian countries by study

\begin{tabular}{|c|c|c|c|c|c|c|}
\hline $\begin{array}{l}\text { Study by } \\
\text { reference } \\
\text { number }\end{array}$ & Country & Type of study & Setting & $\begin{array}{l}\text { Prevalence } \\
\% \text { NAFLD }\end{array}$ & $\begin{array}{l}\text { Number } \\
\text { of subjects }\end{array}$ & $\begin{array}{l}\% \pm 95 \% \\
\text { confidence } \\
\text { interval }\end{array}$ \\
\hline 9 & India & Cohort & Urban/Tertiary & 65.7 & 134 & $65.7 \pm 8.04$ \\
\hline 10 & India & Cross-Sectional & Rural & 30.7 & 176 & $30.7 \pm 6.77$ \\
\hline 11 & India & Cohort & Rural & 28.1 & 302 & $28.1 \pm 5.07$ \\
\hline 12 & India & Cross-Sectional & Urban & 24.7 & 409 & $24.7 \pm 4.18$ \\
\hline 13 & India & Cohort & Urban/Tertiary & 57.2 & 124 & $57.2 \pm 8.71$ \\
\hline 14 & India & Cohort & Urban/Tertiary & 87 & 204 & $87 \pm 4.61$ \\
\hline 15 & India & Cross-Sectional & Urban & 32 & 541 & $32 \pm 3.93$ \\
\hline 16 & India & Cohort & Urban/Suburban & 16.6 & 1168 & $16.6 \pm 2.13$ \\
\hline 17 & Bangladesh & Cohort & Urban/Tertiary & 41.2 & 177 & $41.2 \pm 7.25$ \\
\hline 18 & Bangladesh & Cross-Sectional & Rural & 18.4 & 789 & $18.4 \pm 2.7$ \\
\hline 20 & Pakistan & Cross-Sectional & Urban/Tertiary & 72.4 & 163 & $72.4 \pm 6.86$ \\
\hline 21 & Pakistan & Cross-Sectional & Urban/Tertiary & 51 & 100 & $51 \pm 9.8$ \\
\hline 22 & Sri Lanka & Cohort & Rural & 18 & 403 & $18 \pm 3.75$ \\
\hline 23 & Sri Lanka & Cross Sectional & Rural & 32.6 & 2985 & $32.6 \pm 1.68$ \\
\hline
\end{tabular}

surgery at a tertiary care center ${ }^{9}$ (Table 1 ). In these patients, the average BMI was 44. Not surprisingly, the prevalence of NAFLD was $65.7 \%$ in this population, with $33.6 \%$ having NASH and $14.1 \%$ having advanced fibrosis. ${ }^{9}$

In Table 1, we detail all the studies with the prevalence estimates. Some of the key findings from the articles show that NAFLD is a disease not only in more developed cities but also noted in rural areas. A study in the Indian state of Haryana, showed prevalence of NAFLD to be $30 \%$ in patients from rural villages reporting for US. ${ }^{10}$ Similarly, another study also conducted in rural India last year showed that the prevalence of NAFLD in patients undergoing routine US was $28.1 \%{ }^{11}$ Also of note, NAFLD prevalence, even in non-diabetic patients, was found to be high, with an estimate of $24.7 \%$ in one study for an urban population. ${ }^{12}$ Not surprisingly, the prevalence of NAFLD in diabetics was higher, with reported estimates of $57.2-87 \% .{ }^{13,14}$ The study from Prasanth et al. ${ }^{15}$ utilized review of histologic data and noted a prevalence of $62.6 \%$ for steatohepatitis, with $37 \%$ having fibrosis. The overall data, though, still remains variable, with another study conducted in a suburban population from two cohorts in established 'railway colonies' showing a prevalence of $16.6 \%{ }^{16}$

In Bangladesh, a single published study conducted in a tertiary care liver clinic estimated a prevalence of $42.4 \%$ of biopsy-proven NASH cases. ${ }^{17}$ In comparison to this, a rural study in Bangladesh showed overall prevalence of NAFLD to be $18.4 \% .{ }^{18}$ This either may highlight an underestimation in the rural setting (likely due to the methodology of detection) or an overestimation in tertiary clinic (likely due to referral bias). It is worth noting that a study in London amongst the immigrant Bangladeshi population appeared to show an increased susceptibility to developing NAFLD as compared to Caucasians. ${ }^{19}$ NAFLD was also noted to be more common in diabetic Bangladeshis, with a high prevalence of $59.4 \% .{ }^{17}$ Further future studies are needed to understand underlying potential genetic risk in this population for developing NAFLD.

Data from an urban tertiary care center in Pakistan for Type 2 diabetic patients assessed by US showed an overall prevalence of NAFLD of $72.4 \% .{ }^{20}$ Another study, though conducted in an urban setting in Pakistan, noted a prevalence of $51 \%$ NAFLD in Type II diabetics. ${ }^{21}$ In a study carried out in rural Sri Lanka, NAFLD was noted to be prevalent, at $18 \%{ }^{22}$ Again, as noted in other studies, a different study in an urban setting also showed a higher prevalence of $32.6 \% .^{23}$ We did not find any studies in our search with regard to NAFLD prevalence in the other South Asian nations. Nonetheless, it appears that NAFLD is a global epidemic with increasing prevalence in South Asia.

What are the risk factors associated with development of NAFLD in South Asia?

The risk factors for NAFLD in South Asia appear to be similar to those in the Western world, with some subtle differences. Age, obesity, insulin resistance, and overall development of metabolic syndrome are the major risk factors. ${ }^{1-3}$ Multiple population-based studies from South Asia have revealed an association between HTN, waist circumference, BMI and insulin resistance. ${ }^{7,9,24}$ In 2015, a study specifically looked at risk factors for NAFLD in India and suggested multiple risk factors, including BMI, homeostatic model assessment of insulin resistance (HOMA-IR), waist-hip ratio, diabetes, HTN, family history of metabolic syndrome and sleep apnea. ${ }^{14,15,25}$ Furthermore, certain dietary habits were also associated with NAFLD in India, which included non-vegetarian diet, fried food, spicy food and tea. ${ }^{15} \mathrm{~A}$ similar study revealed higher prevalence of all components of metabolic syndrome in NAFLD patients. ${ }^{10}$ Finally, there are also non-modifiable risk factors associated with south Asian NAFLD that are related to genetic and epigenetic variations, such as in single nucleotide polymorphisms (SNPs). ${ }^{26}$ Interestingly, multiple studies from South Asia also reveal the early-onset of NAFLD, with average age in the $40 \mathrm{~s}$, and a male predominance in this region. $24,26-30$ 


\section{South Asian NAFLD phenotype and "Lean NAFLD"}

The South Asian phenotype of NAFLD appears to differ from that which is presumed in developed nations. South Asian patients that present with NAFLD appear to have lower BMI and obesity rates. ${ }^{7}$ Despite this, the prevalence of NAFLD is significant on this sub-continent. This observation has come to be known as the 'Asian Paradox'. This phenomenon is hypothesized to be related to ethnic disparities in visceral fat distribution. ${ }^{27,28}$ In fact, computed tomography imaging studies evaluating distribution of fat in South Asians has found both subcutaneous and total adipose tissue to correlate with pathological severity of NAFLD. ${ }^{31-33}$

This has also led to concerns regarding the use of nomenclature broadly to define obesity, which may not be accurate in the South Asian population. In fact, the average BMI in South Asian patients is only $\sim 26$ and does not reflect the true risk of developing NAFLD (Table 2). ${ }^{24-28}$ There is further implication, as even non-obese NAFLD has been shown to be an independent risk factor for coronary artery disease in this population. ${ }^{34-36}$ Hence, it is important for clinicians to be aware that Asians with lower BMI are also at increased risk of cardiovascular and metabolic diseases. Additionally, these patients develop insulin resistance despite having lower BMI as compared to western patients and subsequently are still high risk of developing NAFLD. ${ }^{37}$

\section{Implications for burden of HCC in NAFLD patients in South Asia}

HCC remains one of the most common causes of cancerrelated deaths in the South Asian sub-continent, with NAFLD/ NASH presumed to be the cause of a major portion of the inciting disease. ${ }^{38-42}$ Data from GLOBOCAN 2012 showed that 782,000 new cases of HCC were reported that year, with $83 \%$ of those being in the developing world. ${ }^{43}$ Unfortunately, epidemiological studies on incidence of $\mathrm{HCC}$ in the AsiaPacific remain limited. By 2030, it is projected that China and India will have the highest burden of diabetes, with 4 of the 10 countries with the highest prevalence of diabetes also being in Asia (namely Indonesia, Pakistan, Bangladesh, and the Philippines). ${ }^{44}$ Since diabetes has a known association with NAFLD and $\mathrm{NASH}$, the increasing rates of this disease will also have implications on development of HCC.

Longitudinal studies on the natural history of NAFLD in South Asian countries are lacking, but studies from the western countries clearly point to fatty liver progressing to cirrhosis and HCC. ${ }^{45,46}$ It is then worrisome that a similar phenomenon may take place in Asia. True incidence of $\mathrm{NASH}$ leading to HCC is further difficult to ascertain given the relatively long duration from diagnosis of NAFLD to development

Table 2. Average BMI in South Asia listed by study

\begin{tabular}{lll}
\hline $\begin{array}{l}\text { Study by } \\
\text { reference number }\end{array}$ & $\begin{array}{l}\text { Year } \\
\text { of publication }\end{array}$ & $\begin{array}{l}\text { Average } \\
\text { BMI }\end{array}$ \\
\hline 24 & 2014 & 26.14 \\
25 & 2015 & 26.25 \\
28 & 2008 & 25.6 \\
29 & 2006 & 26.7 \\
30 & 2003 & 25.9 \\
\hline
\end{tabular}

of NASH. ${ }^{46}$ From longitudinal studies performed in the West, it has been shown that rates of HCC from NASH are similar to those of HCC from infection with the hepatitis $\mathrm{C}$ virus (HCV). ${ }^{46}$

As of yet, the only longitudinal study that has been published on an Asian population is out of Japan. Yatsuji et al. ${ }^{47}$ showed that the 5-year occurrence rate of HCC in patients with NASHrelated cirrhosis and patients with HCV-related cirrhosis was not statistically different. Amongst available data from the South Asian nations, India has some of the highest rates of NAFLD, and it is possible to roughly estimate rates of NASHassociated HCC from numbers from similar studies. India is estimated to have $\sim 120$ million people with NAFLD, ${ }^{42} 31 \%$ of those patients with demonstrated NASH on histology ${ }^{48}$ (i.e. $\sim 37$ million individuals with NASH).

From studies in Western nations, it has been proposed that $\sim 10 \%$ of NASH patients ${ }^{39,49}$ will go on to develop cirrhosis (i.e. $\sim 3.7$ million individuals). Of them, $\sim 25 \%$ of NASH cirrhotics may go on to develop NASH HCC, ${ }^{49}$ representing almost 1 million patients in India with $\mathrm{NASH}$-related HCC. ${ }^{33}$ Mahady et al. ${ }^{48}$ estimated the prevalence of HCC in another unique way, by utilizing data on the prevalence of diabetes to estimate prevalence of NASH and HCC. Sixtythree million Indians are proposed to have Type 2 diabetes, with $70 \%$ having NAFLD (44 million). ${ }^{50-52}$ Nearly a third are proposed to have NASH (i.e. 13 million). It is projected that $5 \%$ of those with NASH (i.e. $\sim 650,000$ ) may develop HCC. ${ }^{48}$

The studies on prognosis for NASH-related HCC in South Asia are also limited, and to date only studies from Japan exist. The 5-year recurrence rate of NASH HCC as compared to HCV-related HCC were not statistically different. ${ }^{53}$ This differed from a recent USA-based study, where it was found that patients with NASH HCC had better survival rates as compared to those with HCV HCC. ${ }^{54}$ Visceral, rather than overall, body fat has been seen to correlate with occurrence of HCC. ${ }^{55}$ Visceral body fat is related to the degree of inflammation and fibrosis in NASH. The pro-inflammatory environment can impact the liver and other tissues ${ }^{48}$ and patients with more visceral fat had higher rates of HCC recurrence. ${ }^{56}$ This is particularly important in South Asia, given the higher rates of visceral body fat as related to their Western counterparts. ${ }^{38}$

\section{Conclusions}

To conclude, NAFLD is a growing epidemic and is not limited to the Western world. Emerging data notes a high prevalence of NAFLD in the South Asian population. This is likely related to changes in dietary modification from industrialization and development of metabolic risk factors for this disease. Notably, the prevalence of NAFLD is increasing in the South Asian population and there appears to be a male predominance. This population also appears to be predisposed to developing this disease earlier, compared to the Western population. Interestingly, BMI does not fully appreciate the risk of developing this condition in the South Asian population, due to variation in ethnic distribution of adiposity. With the increasing prevalence of NAFLD in this subcontinent, it is becoming clear that it will contribute to increasing incidence of HCC as well, and further population-based studies are needed to understand the risks that may serve to inform future public health initiatives. 


\section{Conflict of interest}

The authors have no conflict of interests related to this publication.

\section{Author contributions}

Review research, manuscript writing and graphic creation (SS), review research, manuscript writing and graphic creation (GNK), mentoring, writing, discussion, guarantor (SS). All authors approved the final submitted version.

\section{References}

[1] Loomba R, Sanyal AJ. The global NAFLD epidemic. Nat Rev Gastroenterol Hepatol 2013;10:686-690. doi: 10.1038/nrgastro.2013.171.

[2] Rinella ME. Nonalcoholic fatty liver disease: a systematic review. JAMA 2015 313:2263-2273. doi: 10.1001/jama.2015.5370.

[3] Farrell GC, Wong VW, Chitturi S. NAFLD in Asia-as common and important as in the West. Nat Rev Gastroenterol Hepatol 2013;10:307-318. doi: 10. 1038/nrgastro.2013.34.

[4] Sharma M, Mitnala S, Vishnubhotla RK, Mukherjee R, Reddy DN, Rao PN. The riddle of nonalcoholic fatty liver disease: progression from nonalcoholic fatty liver to nonalcoholic steatohepatitis. J Clin Exp Hepatol 2015;5:147-158. doi: 10.1016/j.jceh.2015.02.002.

[5] Browning JD, Szczepaniak LS, Dobbins R, Nuremberg P, Horton JD, Cohen JC, et al. Prevalence of hepatic steatosis in an urban population in the United States: impact of ethnicity. Hepatology 2004;40:1387-1395. doi: 10.1002/ hep. 20466.

[6] Petersen KF, Dufour S, Feng J, Befroy D, Dziura J, Dalla Man C, et al. Increased prevalence of insulin resistance and nonalcoholic fatty liver disease in AsianIndian men. Proc Natl Acad Sci U S A 2006;103:18273-18277. doi: 10.1073/ pnas.0608537103.

[7] Liu CJ. Prevalence and risk factors for non-alcoholic fatty liver disease in Asian people who are not obese. J Gastroenterol Hepatol 2012;27:1555-1560. doi: 10.1111/j.1440-1746.2012.07222.x.

[8] Das K, Das K, Mukherjee PS, Ghosh A, Ghosh S, Mridha AR, et al. Nonobese population in a developing country has a high prevalence of nonalcoholic fatty liver and significant liver disease. Hepatology 2010;51:1593-1602. doi: 10. 1002/hep.23567.

[9] Praveenraj P, Gomes RM, Kumar S, Karthikeyan P, Shankar A, Parthasarathi R, et al. Prevalence and predictors of non-alcoholic fatty liver disease in morbidly obese south Indian patients undergoing bariatric surgery. Obes Surg 2015; 25:2078-2087. doi: 10.1007/s11695-015-1655-1.

[10] Majumdar A, Misra P, Sharma S, Kant S, Krishnan A, Pandav CS. Prevalence of nonalcoholic fatty liver disease in an adult population in a rural community of Haryana, India. Indian J Public Health 2016;60:26-33. doi: 10.4103/ 0019-557X.177295.

[11] Anurag L, Aniket S, Shalik J, Amarja L, Dhananjay R, Sachin J. Non-alcoholic fatty liver disease prevalence and associated risk factors-A study from rural sector of Maharashtra. Trop Gastroenterol 2015;36:25-30. doi: 10.7869/ tg. 241 .

[12] Anbalagan VP, Venkataraman V, Vamsi M, Deepa $M$, Mohan V. A simple Indian diabetes risk score could help identify nondiabetic individuals at high risk of non-alcoholic fatty liver disease (CURES-117). J Diabetes Sci Technol 2012; 6:1429-1435. doi: 10.1177/193229681200600624.

[13] Agarwal AK, Jain V, Singla S, Baruah BP, Arya V, Yadav R, et al. Prevalence of non-alcoholic fatty liver disease and its correlation with coronary risk factors in patients with type 2 diabetes. J Assoc Physicians India 2011;59:351-354.

[14] Mohan V, Farooq S, Deepa M, Ravikumar R, Pitchumoni CS. Prevalence of non-alcoholic fatty liver disease in urban south Indians in relation to different grades of glucose intolerance and metabolic syndrome. Diabetes Res Clin Pract 2009;84:84-91. doi: 10.1016/j.diabres.2008.11.039.

[15] Prashanth M, Ganesh HK, Vima MV, John M, Bandgar T, Joshi SR, et al. Prevalence of nonalcoholic fatty liver disease in patients with type 2 diabetes mellitus. J Assoc Physicians India 2009;57:205-210.

[16] Amarapurkar D, Kamani P, Patel N, Gupte P, Kumar P, Agal S, et al. Prevalence of non-alcoholic fatty liver disease: population based study. Ann Hepatol 2007;6:161-163.

[17] Alam S, Noor-E-Alam SM, Chowdhury ZR, Alam M, Kabir J. Nonalcoholic steatohepatitis in nonalcoholic fatty liver disease patients of Bangladesh. World J Hepatol 2013;5:281-287. doi: 10.4254/wjh.v5.i5.281.

[18] Rahman MM, Kibria G, Begum H, Hague M, Sultana N, Akhter M, et al. Prevalence and risk factors of nonalcoholic fatty liver disease in a rural community of south Asia. Gastroenterology 2015;148:S1045-S146. doi: 10.1016/ S0016-5085(15)33567-8.
[19] Alazawi W, Abeysekera K, Boomla K, Foster GR. Population based study of non-alcoholic fatty liver disease (NAFLD) shows disease is more common among Bangladeshis in ethnically diverse boroughs of London. J Hepatol 2013;58:S530. doi: 10.1016/S0168-8278(13)61314-8.

[20] Butt A, Hamid S, Jafri W, Salih M, Haider Z, Akhter J. Prevalence and risk factors of NAFLD among native south Asian Pakistani patients with type 2 diabetes and metabolic syndrome. Am J Gastroenterol 2011;106:S131.

[21] Taseer IH, Hussain L, Safdar S, Mirbahar AM, Ahmad I. Frequency of non alcoholic fatty liver disease (NAFLD) and its biochemical derangements in type-2 diabetic patients. Pak J Med Sci 2009:25:817-820.

[22] Pinidiyapathirage MJ, Dassanayake AS, Rajindrajith S, Kalubowila U, Kato N, Wickremasinghe AR, et al. Non-alcoholic fatty liver disease in a rural, physically active, low income population in Sri Lanka. BMC Res Notes 2011;4:513. doi: 10.1186/1756-0500-4-513.

[23] Dassanayake AS, Kasturiratne A, Rajindrajith S, Kalubowila U, Chakrawarthi $\mathrm{S}$, De Silva AP, et al. Prevalence and risk factors for non-alcoholic fatty liver disease among adults in an urban Sri Lankan population. J Gastroenterol Hepatol 2009;24:1284-1288. doi: 10.1111/j.1440-1746.2009.05831.x.

[24] Singh SP, Kar SK, Panigrahi MK, Misra B, Pattnaik K, Bhuyan P, et al. Profile of patients with incidentally detected nonalcoholic fatty liver disease (IDNAFLD) in coastal eastern India. Trop Gastroenterol 2013;34:144-152. doi: $10.7869 / \mathrm{tg} .118$.

[25] Singh SP, Singh A, Misra D, Misra B, Pati GK, Panigrahi MK, et al. Risk factors associated with non-alcoholic fatty liver disease in Indians: a case-control study. J Clin Exp Hepatol 2015;5:295-302. doi: 10.1016/j.jceh.2015.09. 001.

[26] Chatterjee A, Basu A, Chowdhury A, Das K, Sarkar-Roy N, Majumder PP, et al. Comparative analyses of genetic risk prediction methods reveal extreme diversity of genetic predisposition to nonalcoholic fatty liver disease (NAFLD) among ethnic populations of India. J Genet 2015;94:105-113. doi: 10.1007/s12041-015-0494-0.

[27] Dey PK, Sutradhar SR, Barman TK, Khan NA, Hasan I, Haque MF, et al. Risk factors of non-alcoholic fatty liver disease. Mymensingh Med J 2013;22:649654.

[28] Singh DK, Sakhuja P, Malhotra V, Gondal R, Sarin SK. Independent predictors of steatohepatitis and fibrosis in Asian Indian patients with non-alcoholic steatohepatitis. Dig Dis Sci 2008;53:1967-1976. doi: 10.1007/s10620007-0074-0.

[29] Madan K, Batra Y, Gupta SD, Chander B, Rajan KD, Tewatia MS, et al. Nonalcoholic fatty liver disease may not be a severe disease at presentation among Asian Indians. World J Gastroenterol 2006;12:3400-3405. doi: 10. 3748/wjg.v12.i21.3400.

[30] Singh SP, Nayak S, Swain M, Rout N, Mallik RN, Agarwal O, et al. Prevalence of nonalcoholic fatty liver disease in coastal eastern India: a preliminary ultrasonographic survey. Trop Gastroenterol 2004;25:76-79.

[31] Wong RJ, Ahmed A. Obesity and non-alcoholic fatty liver disease: Disparate associations among Asian populations. World J Hepatol 2014;6:263-273. doi: 10.4254/wjh.v6.i5.263.

[32] Duseja A, Chalasani N. Epidemiology and risk factors of nonalcoholic fatty liver disease (NAFLD). Hepatol Int 2013;7 Suppl 2:755-764. doi: 10. 1007/s12072-013-9480-X.

[33] Choudhary NS, Duseja A, Kalra N, Das A, Dhiman RK, Chawla YK. Correlation of adipose tissue with liver histology in Asian Indian patients with nonalcoholic fatty liver disease (NAFLD). Ann Hepatol 2012;11:478-486.

[34] Das K, Das K, Mukherjee PS, Ghosh A, Ghosh S, Mridha AR, et al. Nonobese population in a developing country has a high prevalence of nonalcoholic fatty liver and significant liver disease. Hepatology 2010;51:1593-1602. doi: 10.1002/hep.23567.

[35] Vendhan R, Amutha A, Anjana RM, Unnikrishnan R, Deepa M, Mohan V. Comparison of characteristics between nonobese and overweight/obese subjects with nonalcoholic fatty liver disease in a South Indian population. Diabetes Technol Ther 2014;16:48-55. doi: 10.1089/dia.2013.0165.

[36] Thakur ML, Sharma S, Kumar A, Bhatt SP, Luthra K, Guleria R, et al. Nonalcoholic fatty liver disease is associated with subclinical atherosclerosis independent of obesity and metabolic syndrome in Asian Indians. Atherosclerosis 2012;223:507-511. doi: 10.1016/j.atherosclerosis.2012.06.005.

[37] Bhat G, Baba CS, Pandey A, Kumari N, Choudhuri G. Insulin resistance and metabolic syndrome in nonobese Indian patients with non-alcoholic fatty liver disease. Trop Gastroenterol 2013;34:18-24. doi: 10.7869/tg.2012.86.

[38] Vongsuvanh R, van der Poorten D, George J. Non-alcoholic fatty liver diseaserelated hepatocellular carcinoma: a sleeping tiger in the Asia Pacific. Hepatol Int 2013;7:823-832. doi: 10.1007/s12072-013-9453-0.

[39] Starley BQ, Calcagno CJ, Harrison SA. Nonalcoholic fatty liver disease and hepatocellular carcinoma: a weighty connection. Hepatology 2010;51: 1820-1832. doi: 10.1002/hep.23594

[40] Page JM, Harrison SA. NASH and HCC. Clin Liver Dis 2009;13: 631-647. doi: 10.1016/j.cld.2009.07.007.

[41] Forner A, Bruix J. Biomarkers for early diagnosis of hepatocellular carcinoma. Lancet Oncol 2012;13:750-751. doi: 10.1016/S1470-2045(12)70271-1. 


\section{Singh S. et al: NAFLD in South Asians}

[42] Sherman M. Epidemiology of hepatocellular carcinoma. Oncology 2010;78: 7-10. doi: 10.1159/000315223.

[43] Liver Cancer. Available from: http://globocan.iarc.fr/old/FactSheets/cancers/liver-new.asp, accessed at September 2016.

[44] Ramachandran A, Ma RC, Snehalatha C. Diabetes in Asia. Lancet 2010;375: 408-418. doi: 10.1016/S0140-6736(09)60937-5

[45] Bhala N, Angulo P, van der Poorten D, Lee E, Hui JM, Saracco G, et al. The natura history of nonalcoholic fatty liver disease with advanced fibrosis or cirrhosis: an international collaborative study. Hepatology $2011 ; 54: 1208-1216$. doi: 10 . 1002/hep.24491.

[46] Adams LA, Lymp JF, St Sauver J, Sanderson SO, Lindor KD, Feldstein A, et al. The natural history of nonalcoholic fatty liver disease: a population-based cohort study. Gastroenterology 2005;129:113-121. doi: 10.1053/j.gastro. 2005.04.014.

[47] Yatsuji S, Hashimoto E, Tobari M, Taniai M, Tokushige K, Shiratori K. Clinical features and outcomes of cirrhosis due to non-alcoholic steatohepatitis compared with cirrhosis caused by chronic hepatitis C. J Gastroenterol Hepatol 2009;24:248-254. doi: 10.1111/j.1440-1746.2008.05640.x.

[48] Mahady SE, George J. The future liver of the Asia pacific: fatter and firmer from more fructose and fortune? J Clin Exp Hepatol 2013;3:106-113. doi: 10.1016/j.jceh.2012.10.011.

[49] Agarwal S, Duseja AK. Non-alcoholic fatty liver disease: east versus west. J Clin Exp Hepatol 2012;2:122-134. doi: 10.1016/S0973-6883(12)60101-7.
[50] Prashanth M, Ganesh HK, Vima MV, John M, Bandgar T, Joshi SR, et al. Prevalence of nonalcoholic fatty liver disease in patients with type 2 diabetes mellitus. J Assoc Physicians India 2009;57:205-210.

[51] Gupte P, Amarapurkar D, Agal S, Baijal R, Kulshrestha P, Pramanik S, et al. Non-alcoholic steatohepatitis in type 2 diabetes mellitus. J Gastroenterol Hepatol 2004;19:854-858. doi: 10.1111/j.1440-1746.2004.03312.x.

[52] Targher G, Bertolini L, Rodella S, Tessari R, Zenari L, Lippi G, et al. Nonalcoholic fatty liver disease is independently associated with an increased incidence of cardiovascular events in type 2 diabetic patients. Diabetes Care 2007;30:2119-2121. doi: 10.2337/dc07-0349.

[53] Rosmordue O, Fartoux L. HCC and NASH: How strong is the clinical demonstration? Clin Res Hepatol Gastroenterol 2012;36:202-208. doi: 10.1016/j. clinre.2011.12.011.

[54] Tokushige K, Hashimoto E, Yatsuji S, Tobari M, Taniai M, Torii N, et al. Prospective study of hepatocellular carcinoma in nonalcoholic steatohepatitis in comparison with hepatocellular carcinoma caused by chronic hepatitis C. J Gastroenterol 2010;45:960-967. doi: 10.1007/s00535-010-0237-1.

[55] Reddy SK, Steel JL, Chen HW, DeMateo DJ, Cardinal J, Behari J, et al. Outcomes of curative treatment for hepatocellular cancer in nonalcoholic steatohepatitis versus hepatitis $\mathrm{C}$ and alcoholic liver disease. Hepatology 2012; 55:1809-1819. doi: 10.1002/hep.25536.

[56] Vongsuvanh R, George J, Qiao L, van der Poorten D. Visceral adiposity in gastrointestinal and hepatic carcinogenesis. Cancer Lett 2013;330:1-10. doi: 10.1016/j.canlet.2012.11.038. 